\title{
Giant visual evoked potentials and their related factors in Mexican patients
}

\author{
Alfonso Hernández-Zepedaํ, Josefina Hernández-Cervantes ${ }^{1}$, Jorge Varela-Blanco ${ }^{1}$, Silvia García ${ }^{1}$, \\ Luis B. Enríquez-Sánchez ${ }^{2 *}$, David A. Aguirre-Baca ${ }^{3}$, Javier Camarillo-Cisneros ${ }^{3}$, and Luis C. Hinojos-Gallardo ${ }^{3}$ \\ ${ }^{1}$ Department of Clinical Neurophysiology, Centro Médico Nacional 20 de Noviembre, Instituto de Seguridad y Servicios Sociales de los Trabajadores \\ del Estado, Mexico City; ${ }^{2}$ Departament of General Surgery, Central State Hospital, Chihuahua, Chihuahua; ${ }^{3}$ Departament of Medicine, Faculty of \\ Medicine and Biomedical Sciences, Universidad Autónoma de Chihuahua, Chihuahua, Chihuahua, Mexico
}

\begin{abstract}
Background: In the analysis of electrical signals evoked through the application of appropriate stimuli to special sensory systems, the prolongation of latency and the incremented amplitude of the components studied are generally considered fundamental anomalies. However, the exaggerated increase in amplitude can also be an indicator of dysfunction in the central nervous system. Objective: The objective of the study was to evaluate giant visual evoked potentials (VEPS) and their related factors in patients at the Centro Médico Nacional (CMN) 20 de Noviembre. Materials and methods: At the CMN 20 de Noviembre, a descriptive, observational, and cross-sectional analysis of patients was performed at the Clinical Neurophysiology service, which found giant VEPS in the period from 2012 to 2018. The information obtained was from the clinical record of patients who met the selection criteria of the population to be studied. The IBM SPSS version 22.0 program was used for the statistical analysis. Results: A total sample of 36 patients was collected; the average age of the patients included in the study was 25.61 months. To improve and standardize the management of information, the population was divided into six categories according to the age group to which they belonged. The most frequent comorbidity of the patients was prematurity, observed in $63.9 \%(n=23)$. No statistically significant difference was observed in the distribution of findings found in the different amplitudes and latencies regarding the age of the patient. Conclusions: There are greater latency and less amplitude in patients with giant visual evoked potentials.
\end{abstract}

Key words: Evoked potentials. Amplitude. Latency.

\section{Potenciales visuales gigantes evocados y sus factores relacionados en pacientes mexicanos}

\section{Resumen}

Antecedentes: En el análisis de las señales eléctricas evocadas mediante la aplicación de estímulos apropiados a sistemas sensoriales especiales, la prolongación de la latencia y la disminución de la amplitud de los componentes estudiados se consideran generalmente anomalías fundamentales. Sin embargo, el aumento exagerado de la amplitud también puede ser indicador de disfunción del sistema nervioso central (SNC). Objetivo: Evaluar potenciales evocados visuales gigantes y

Correspondence:

*Luis B. Enríquez-Sánchez

E-mail: investigacionhcu@gmail.com
Available online: 11-02-2021

Rev Mex Neuroci. 2021;22(1):15-21

www.revmexneurociencia.com

1665-5044/ @ 2020 Academia Mexicana de Neurología A.C. Published by Permanyer. This is an open access article under the CC BY-NC-ND license (http://creativecommons.org/licenses/by-nc-nd/4.0/). 
factores relacionados en pacientes en el Centro Médico Nacional (CMN) 20 de Noviembre. Materiales and métodos: Se realizó un análisis descriptivo, observacional y transversal en el CMN 20 de Noviembre de pacientes del Servicio de neurofisiología clínica en quienes se encontraron potenciales evocados visuales gigantes en el período 2012-2018. La información obtenida procede del expediente clínico de los pacientes que cumplieron los criterios de selección de la población a estudiar. Para el análisis estadístico se utilizó el programa IBM SPSS versión 22.0. Resultados: Se recogió una muestra de 36 pacientes; la edad media de los pacientes incluidos en el estudio fue de 25.61 meses. Para mejorar y estandarizar el manejo de la información, la población se dividió en seis categorías según el grupo de edad al que pertenecía. La comorbilidad más frecuente de los pacientes fue nacimiento prematuro, observada en $63,9 \%(n=23)$. No se observaron diferencias estadísticamente significativas en los hallazgos de distribución de las amplitudes y latencias con respecto a la edad del paciente. Conclusiones: Hay una mayor latencia y una menor amplitud en los pacientes con potenciales evocados visuales gigantes.

Palabras clave: Potenciales evocados. Amplitud. Latencia.

\section{Introduction}

Visual evoked potentials (VEPs) are visually evoked electrophysiological signals extracted from electroencephalographic activity in the visual cortex, recorded on the scalp 1 . Giant evoked potentials (poly(ethylene glycol) [PEGs]) are cortical evoked potentials that were initially described by Dawson in 1947 in patients with sensory stimulus reflex myoclonus ${ }^{2,3}$. They have also been described in many other disorders, primarily related to cortical myoclonus associated with progressive myoclonic epilepsy, idiopathic epilepsy, as well as toxic, metabolic, and infectious myoclonus. However, its clinical significance is not clearly defined, and its presence does not necessarily imply a pathology of the central nervous system (CNS) ${ }^{2-5}$.

The amplitude of an evoked component can be measured from the baseline to the maximum peak or from the peak of one component to the peak of the next component with inverted polarity ${ }^{6}$. Multiple nosological entities have a common factor: the genesis of cortical evoked responses of great amplitude. These have been commonly called giant evoked potentials (PEG). In most cases, these are conditions that have the common clinical characteristic of the presence of myoclonus of cortical origin, such as progressive myoclonic epilepsy $^{7}$ and myoclonus of toxic origin ${ }^{8}$.

VEPs are of particular clinical utility in determining a physiological abnormality where neurological and ophthalmological examinations are normal. VEPs are extremely sensitive and can detect a non-discernible dysfunction at the level of a neurological, ophthalmological examination, or another type of revision. The primary measurement of clinical interest is the latency of P100 after stimulus application. The abnormality is particularly clear if the P100 is normal after stimulation of the other eye, more posterior and chiasmatic lesions or a generalized cerebral dysfunction can cause a bilateral prolongation of the $\mathrm{P} 100$, usually with similar prolongation when testing each eye separately ${ }^{9}$.

\section{Methods}

At the Centro Médico Nacional (CMN) 20 de Noviembre, a descriptive, observational, and cross-sectional analysis of patients was performed at the Clinical Neurophysiology Service, which found giant VEPs in the period from 2012 to 2018 . The information obtained was from the clinical file of the patients that met the selection criteria of the population to study. The inclusion criteria were: patients of all ages, patients with identification of giant VEPs in at least two replicas for each side studied, and that they had a complete record with all the variables to study (age, gender, latency, and amplitude of the VEPs, signs, and symptoms on the occasion of shipment, the time elapsed from the beginning of the symptomatology to the realization of the VEPs, diagnoses at the time of the study of the VEPs, the pharmacological treatment used at the time of the study). VEPs were defined as (N75-P100) $>18 \mu \mathrm{V}$. The exclusion criteria were patients who did not strictly comply with the definition of giant evoked potentials and in whom there is not a minimum of two replicas with giant evoked potentials on each side studied. The elimination criterion was that there was incomplete information in the clinical file.

In the descriptive analysis, central tendency and dispersion measurement were handled, as well as proportions. For the statistical analysis, the IBM SPSS version 22.0 for Windows program was used. The resulting variables will be compared using the Student's t-test when they are measured in ratio scale and with Fisher's square or exact test when they are variables in the 
Table 1. Comparison of the patient's age with the findings noticed in poly(ethylene glycol) at the Centro Médico Nacional 20 de Noviembre from 2012 to 2018

\begin{tabular}{|l|l|c|c|c|}
\hline & Interpretation & N & $\begin{array}{c}\text { Age } \\
\text { (months) }\end{array}$ & p \\
\hline $\begin{array}{l}\text { Right } \\
\text { amplitude }\end{array}$ & Normal & 14 & 29.64 & 0.52 \\
\hline Left amplitude & Incremented & 22 & 24.05 & 0.55 \\
\hline & Normal & 9 & 23 & 0.66 \\
\hline Right latency & Normal & 23 & 29.22 & 0.34 \\
\hline & Prolonged & 13 & 20.92 & 0.25 \\
\hline Left latency & Normal & 24 & 28.71 & 0.40 \\
\hline & Prolonged & 12 & 21.25 & 0.30 \\
\hline
\end{tabular}

nominal scale. A significant difference will be taken when a "p" $<0.05$ is obtained.

\section{Results}

A descriptive analysis was carried out at the CMN 20 de Noviembre in Mexico City. The study included patients of any age, who had their VEP in at least two replicas for each side, and who had a complete record in the service with all of the variables to be studied at the Neurophysiology Service Clinic from 2012 to 2018. The data collected were age (in months), sex, referral service, shipping diagnosis, pharmacological treatment, values obtained of amplitude (right and left), and latency (right and left).

A total sample of 36 patients was collected. The average age was 25.61 months (standard deviation 25.27 months, minimum 1 month, and maximum 96 months), of which $50 \%(n=18)$ of the sample corresponds to the male gender and $50 \%(n=18)$ to female gender. The most frequent comorbidity of the patients was prematurity, observed in $63.9 \%(n=23)$. No statistically significant difference was observed in the distribution of findings found in the different amplitudes and latencies concerning the patient's age (Table 1). However, a statistically significant difference was found in the variable of right and left amplitude with respect to gender (Table 2).

To improve and standardize information management, the population was divided into six categories according to the age group to which they belonged (Table 3). Analysis of variance was performed according to the age groups previously described to find the
Table 2. Comparison of the patient's sex with the findings noticed in poly(ethylene glycol) at the Centro Médico Nacional 20 de Noviembre from 2012 to 2018

\begin{tabular}{|l|l|c|c|c|}
\hline & Interpretación & Male (\%) & Female (\%) & p \\
\hline $\begin{array}{l}\text { Right } \\
\text { amplitude }\end{array}$ & Normal & $11(61.1)$ & $3(16.7)$ & 0.008 \\
\cline { 1 - 5 } & Incremented & $7(38.9)$ & $15(83.3)$ & \\
\hline $\begin{array}{l}\text { Left } \\
\text { amplitude }\end{array}$ & Normal & $1(5.6)$ & $8(44.4)$ & 0.009 \\
\cline { 1 - 5 } & Incremented & $17(94.4)$ & $10(55.6)$ & \\
\hline $\begin{array}{l}\text { Right } \\
\text { latency }\end{array}$ & Normal & $13(72.2)$ & $10(55.6)$ & 0.24 \\
\hline $\begin{array}{l}\text { Left } \\
\text { latency }\end{array}$ & Nolonged & $5(27.8)$ & $8(44.4)$ & \\
\hline & Normal & $13(72.2)$ & $11(61.1)$ & 0.36 \\
\hline
\end{tabular}

Table 3. Division by age groups of the studied population

\begin{tabular}{|l|c|c|c|}
\hline Group & Age (months) & $\mathbf{n}$ & Percentage \\
\hline 1 & Up to 6 & 4 & 11.1 \\
\hline 2 & $7-12$ & 15 & 41.7 \\
\hline 3 & $13-18$ & 4 & 11.1 \\
\hline 4 & $19-24$ & 3 & 8.3 \\
\hline 5 & $25-48$ & 6 & 16.7 \\
\hline 6 & Above to 49 & 4 & 11.1 \\
\hline
\end{tabular}

mean and standard deviation of the variables of amplitude (right and left) and latency (right and left). In the group of children up to 6 months old, a mean value in the right amplitude of $16.44 \mathrm{uV}$ (standard deviation of $5.25 \mathrm{uV}$, minimum $10 \mathrm{uV}$, and maximum $22 \mathrm{uV}$ ) was found. In patients from 7 to 12 months old, the average value found was of 21.23 uV (standard deviation 14.87, minimum $6 \mathrm{uV}$, and maximum $56 \mathrm{uV}$ ). In the group of patients from 13 to 18 months old, an average of $26.70 \mathrm{uV}$ was found (standard deviation of 8.43, minimum $20 \mathrm{uV}$, and maximum $38 \mathrm{uV}$ ). Patients from 19 to 24 months of age had a mean of $26.97 \mathrm{uV}$ (standard deviation of $8.88 \mathrm{uV}$, minimum $20 \mathrm{uV}$, and maximum $37 \mathrm{uV}$ ). In patients with ages 25-48 months, mean right amplitude of $16.78 \mathrm{uV}$ was found (standard deviation $9.21 \mathrm{uV}$, minimum $4 \mathrm{uV}$, and maximum $26 \mathrm{uV}$ ), and in the group over 49 months old, an average of $16.49 \mathrm{uV}$ was found (standard deviation $11.50 \mathrm{uV}$, minimum 7 , and maximum 23); taking into account all the data obtained, an average of $20.51 \mathrm{uV}$ (standard deviation 11.5, 
Table 4. Analysis of amplitude and latency means by age group in patients undergoing visual evoked potentials from 2012 to 2018 at the Centro Médico Nacional 20 de Noviembre

\begin{tabular}{|l|c|c|c|c|c|c|c|}
\hline & Up to $\mathbf{6}$ months & $\mathbf{7 - 1 2}$ months & $\mathbf{1 3 - 1 8}$ months & $\mathbf{1 9 - 2 4}$ months & $\mathbf{2 5 - 4 8}$ months & Above 49 months & $\mathbf{p}$ \\
\hline Right amplitude (uV) & 16.44 & 21.23 & 26.70 & 26.97 & 16.78 & 16.49 & 0.60 \\
\hline Left amplitude (uV) & 21.91 & 22.85 & 16.23 & 24.37 & 23.25 & 20.05 & 0.84 \\
\hline Right latency (mseg) & 136 & 155.33 & 143.5 & 133.67 & 134.67 & 142.36 & 0.46 \\
\hline Left latency (mseg) & 139.25 & 149.20 & 137.25 & 139.67 & 137.17 & 140.08 & 0.51 \\
\hline
\end{tabular}

minimum 4, and maximum 56), and a "p" $=0.609$ of the right amplitude was obtained.

In the same way, statistical analysis was performed for the values obtained in left amplitude, finding an average measurement in patients up to 6 months of $21.91 \mathrm{uV}$ (standard deviation $17.35 \mathrm{uV}$, minimum $7 \mathrm{uV}$, and maximum $46 \mathrm{uV}$ ). In the group from 7 to 12 months, an average of $22.85 \mathrm{uV}$ was found (standard deviation $9.19 \mathrm{uV}$, minimum $7 \mathrm{uV}$, and maximum $42 \mathrm{uV}$ ). In 13-18 months patients, an average of $16.23 \mathrm{uV}$ was obtained (standard deviation $12.29 \mathrm{uV}$, minimum $2 \mathrm{uV}$, and maximum $31 \mathrm{uV}$ ). In patients aged 19-24 months, they had a mean of $24.37 \mathrm{uV}$ (standard deviation $8.33 \mathrm{uV}$, minimum $17 \mathrm{uV}$, and maximum $33 \mathrm{uV}$ ). In patients from 25 to 48 months, a mean of $23.25 \mathrm{uV}$ was found (standard deviation of $2.37 \mathrm{uV}$, minimum $20 \mathrm{uV}$, and maximum $27 \mathrm{uV}$ ), and in patients older than 49 months, an average of $20.05 \mathrm{uV}$ was found (standard deviation $5.47 \mathrm{uV}$, minimum $13 \mathrm{uV}$, and maximum $27 \mathrm{uV}$ ); the average of the 36 values evaluated for the left amplitude was $21.89 \mathrm{uV}$ (standard deviation of $9.32 \mathrm{uV}$, minimum $2 \mathrm{uV}$, and maximum $46 \mathrm{uV}$ ) and a "p" $=0.847$. For the right latency, in the group of patients up to 6 months of age, an average of $136 \mathrm{~ms}$ was obtained (standard deviation $30 \mathrm{~ms}$, min $120 \mathrm{~ms}$, and maximum $181 \mathrm{~ms}$ ). In the group of patients from 7 to 12 months, an average of $155 \mathrm{~ms}$ was reported (standard deviation of $41.8 \mathrm{~ms}$, minimum $108 \mathrm{~ms}$, and maximum $258 \mathrm{~ms}$ ). In patients from 13 to 18 months, an average of $143.5 \mathrm{~ms}$ was obtained (standard deviation $28.9 \mathrm{~ms}$, minimum $110 \mathrm{~ms}$, and maximum $177 \mathrm{~ms}$ ). The average found in patients aged 19-24 months was $133.67 \mathrm{~ms}$ (standard deviation of $25.0 \mathrm{~ms}$, minimum $105 \mathrm{~ms}$, and maximum $151 \mathrm{~ms}$ ), in patients aged from 25 to 48 months, they had an average of $134.67 \mathrm{~ms}$ (standard deviation of $32.5 \mathrm{~ms}$, minimum $107 \mathrm{~ms}$, and maximum $194 \mathrm{~ms}$ ), and in the group of patients older than 49 months there was an average of $117 \mathrm{~ms}$ (standard deviation of $11.74 \mathrm{~ms}$, minimum $102 \mathrm{~ms}$, maximum 129). For the right latency, a global average of $142.36 \mathrm{~ms}$ was obtained (standard deviation of $34,859 \mathrm{~ms}$, min $102 \mathrm{~ms}$, and $\max 258 \mathrm{~ms}$ ) with a "p" $=0.460$. Statistical analysis was also performed to assess left latency by groups and overall, in patients younger than 6 months. They obtained an average of $139.25 \mathrm{~ms}$ (standard deviation of $25.35 \mathrm{~ms}$, minimum $119 \mathrm{~ms}$, and maximum $176 \mathrm{~ms}$ ). In the group of patients 7-12 months, an average of $149.2 \mathrm{~ms}$ was observed (standard deviation of $33.9 \mathrm{~ms}$, minimum $106 \mathrm{~ms}$, and max $200 \mathrm{~ms}$ ). The average found in patients aged 13-18 months was $137.25 \mathrm{~ms}$ (standard deviation 25.6, minimum $115 \mathrm{~ms}$, and maximum $174 \mathrm{~ms}$ ). In the group of patients from 19 to 24 months, an average of $139.67 \mathrm{~ms}$ was found (standard deviation $27.46 \mathrm{~ms}$, minimum $108 \mathrm{~ms}$, and maximum $157 \mathrm{~ms}$ ). In patients from 25 to 48 months, an average was determined of $137.17 \mathrm{~ms}$ (standard deviation 34.8 ms, minimum $102 \mathrm{~ms}$, and maximum $198 \mathrm{~ms}$ ), and in patients older than 49 months, an average of $114.25 \mathrm{~ms}$ (standard deviation $7.1 \mathrm{~ms}$, minimum $106 \mathrm{~ms}$, and maximum $123 \mathrm{~ms}$ ); the global left latency values had an average of $140.08 \mathrm{~ms}$ (standard deviation of $30.1 \mathrm{~ms}$, range $102-200 \mathrm{~ms}$ ), and a "p" $=0.51$ was obtained. $\mathrm{A}$ compilation of the previous data can be seen in table 4 .

Right amplitude data were matched with right latency and used Fisher's exact test getting a "p" $=0.62$ and a correlation of $16.7 \%$; in the same way, it was performed with data of left amplitude and left latency obtaining a "p" $=0.626$ and a correlation of $17.1 \%$. Dispersion data graph was made comparing the distribution of means by age groups of right amplitude and right latency, as well as left amplitude and left latency; observing in both graphs that at greater latency there is a less amplitude (Figures 1 and 2).

\section{Discussion}

Visual function is considered one of the most important perceptions for development. During motor development, vision provides crucial feedback to the vestibular and 


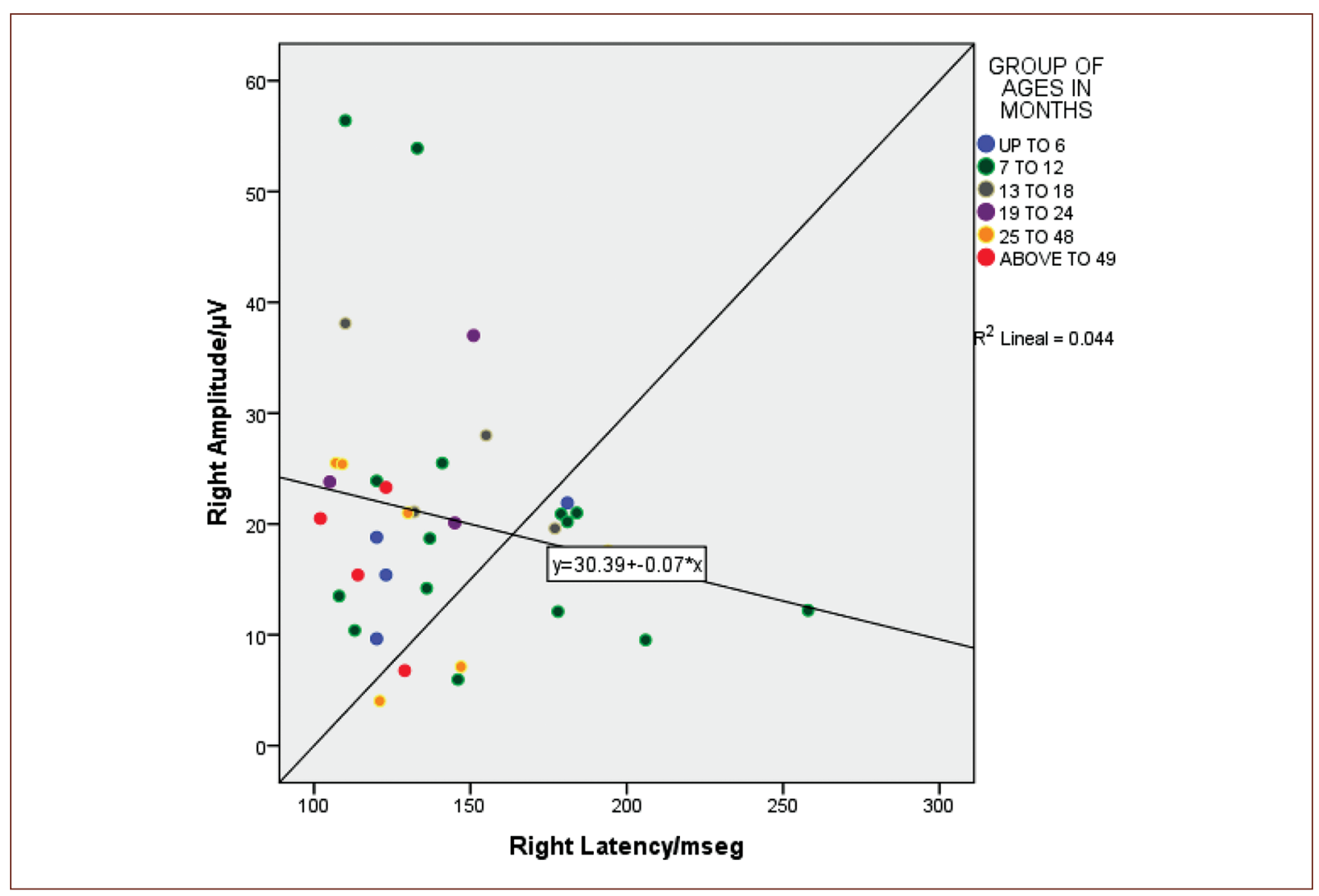

Figure 1. Dispersion by age groups of average right amplitude and right latency in patients undergoing visual evoked potentials at the Centro Médico Nacional 20 de Noviembre from 2012 to 2018.

proprioceptive systems. The vision allows the development of integrative functions such as hand-eye coordination, visual-manual-oral coordination, learning and object recognition, and learning and visual-spatial recognition.

VEPs are averaged cortical potentials that assess the integrity of the visual pathway. They are easily detectable in premature infants and show a different pattern of maturation. They have shown that they can predict adverse prognoses in infants with generalized CNS conditions, particularly hypoxic-ischemic encephalopathies.

The giant evoked potentials are evoked potentials that were first described by Dawson in 1947 in patients with myoclonus reflex to the sensory stimulus. They have also been described in other disorders, primarily related to cortical myoclonus associated with progressive myoclonic epilepsies (e.g., neuronal ceroid lipofuscinosis, Lafora disease, and mitochondrial cytopathies), generalized idiopathic epilepsies, post-anoxic, toxic, and infectious myoclonus ${ }^{3}$.

In the present study, which was carried out at the CMN 20 de Noviembre of the Instituto de Seguridad y Servicios Sociales de los Trabajadores del Estado, after analyzing the information collected in the period from 2012 to 2018 of the patients who met the inclusion criteria, a total sample of 36 patients was collected. The average age was 25.61 months, of which $50 \%$ of the sample corresponds to the male gender and $50 \%$ to the female gender. The most frequent comorbidity of the patients was prematurity, observed in $63.9 \%(n=23)^{3}$.

At the time of correlating the variables found, it was generally found that the greater the latency, the lower the amplitude, and a statistically significant difference was found in the variable of right and left amplitude with respect to gender. That is that the amplitude for the right side was significantly increased in female patients compared to male patients, while the amplitude for the left side was significantly increased in male patients compared to female patients. The above, together with the fact that the total sample corresponds to the same proportion of patients concerning gender, give greater validity to the finding, which could indicate a certain correlation of predominance of the side affected depending on gender. This could probably be related to the physiological and structural differences between 


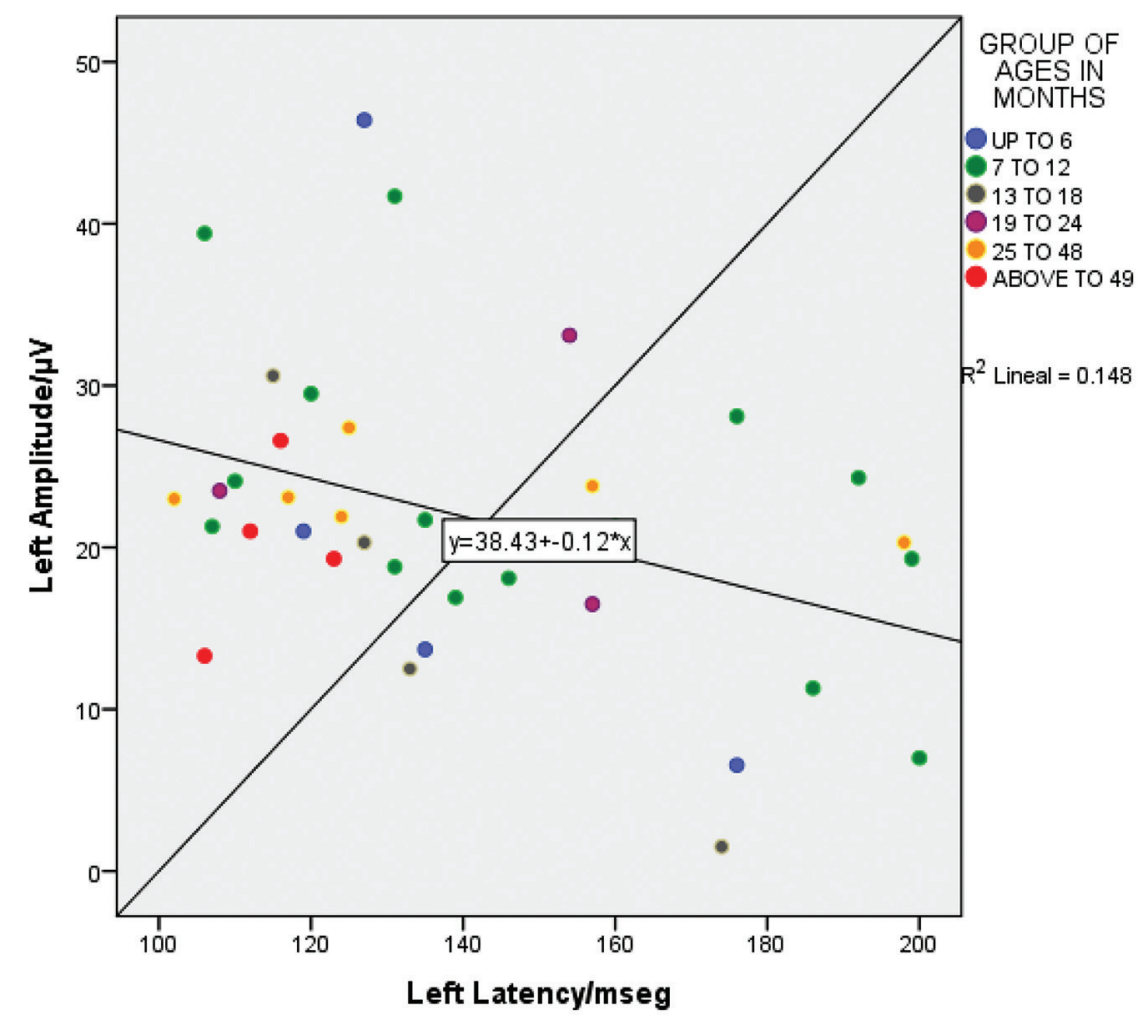

Figure 2. Dispersion by age groups of mean left amplitude and left latency in patients undergoing visual evoked potentials at the Centro Médico Nacional 20 de Noviembre from 2012 to 2018.

genders. This finding has not been documented in the published literature. On the other hand, only 1 patient $(2.7 \%)$ of the total sample had the diagnosis of epilepsy (West Syndrome) in which an increase in the amplitudes of the VEP for both sides was found, which is related to the possible presence of cortical hyperexcitability described in the reference literature ${ }^{3,10}$.

Another aspect that must be taken into consideration is the finding that most of the patients with giant VEPs were premature $(63.9 \%$ of the total sample). This was a precedent and the reason for being sent. Such findings had not been previously reported in the literature and one of the hypotheses could be the fact that in the $1^{\text {st }}$ year of life, there are lower impedances specific to the characteristics of the tissues at those ages such as the dimensions (thickness of skin and bone).

It must be admitted that the present study has multiple limitations due to its design: the number of the sample and the quantity of factors studied. However, it is important to add that this could be considered a pivotal study that can establish the basis for studies of greater statistical value such as prospective studies of control cases among others. Furthermore, due to the small sample, it was not possible to perform significant correlations between various factors. In such case, considering increasing the sample and including more factors such as metabolic, hemodynamic, and anthropometric measurements, results with greater statistical significance can be obtained.

Another possibility of study that can be considered based on the present and considering the theory of cortical hyperexcitability could be the performance of electroencephalograms in patients with giant VEPs and their correlation.

At present, no study in the published literature meets the characteristics of the present study, so in the present work, we tried to provide support for another possible utility for the evoked visual potentials. It was demonstrated by a statistical analysis that related factors exist with statistical significance, and this establishes the basis for further study on the subject.

\section{Conclusion}

It was generally verified that the greater the latency, there is less amplitude, and a statistically significant 
difference was found in the variable of right and left amplitude with respect to gender. That is that the amplitude for the right side was significantly increased in female patients compared to male patients, while the amplitude for the left side was significantly increased in male patients compared to female patients. Furthermore, most of the patients with giant VEPs were premature; this has not been reported before. A possible explanation is because, in the $1^{\text {st }}$ years of life, there are lower impedances specific to the characteristics of the tissues at those ages.

No significant correlation was found between the associations of the rest of the variables.

\section{Funding}

No targeted funding reported.

\section{Con『icts of interest}

The authors declare that they have no conflicts of interest.

\section{Ethical disclosures}

Protection of human and animal subjects. The authors declare that no experiments were performed on humans or animals for this study.
Con $\nabla$ dentiality of data. The authors declare that they have followed the protocols of their work center on the publication of patient data.

Right to privacy and informed consent. The authors declare that no patient data appear in this article.

\section{References}

1. Odom JV, Bach M, Brigell M, Holder GE, McCulloch DL, Mizota A, et al. ISCEV standard for clinical visual evoked potentials: (2016 update). Doc Ophthalmol. 2016;133:1-9

2. Dawson GD. Cerebral responses to electrical stimulation of peripheral nerve in man. J Neurol Neurosurg Psychiatry. 1947;10:134-40.

3. Martín-Palomeque G, Castro-Ortiz A, Pamplona-Valenzuela P, Saiz-Sepúlveda MÁ, Cabañes-Martínez L, López JR. Large amplitude cortica evoked potentials in nonepileptic patients. Reviving an old neurophysiologic tool to help detect CNS pathology. J Clin Neurophysiol. 2017:34:84-91.

4. Liepert J, Haueisen J, Hegemann S, Weiller C. Disinhibition of somatosensory and motor cortex in mitochondriopathy without myoclonus. Clin Neurophysiol. 2001;112:917-22.

5. Ng K, Jones S. The "enhanced N35" somatosensory evoked potential: its associations and potential utility in the clinical evaluation of dystonia and myoclonus. J Neurol. 2007:254:46-52.

6. Baez Martín MM, Gómez Fernández L, Cabrera Abreu I, Alvarez González L, Araujo F. Giant evoked potentials. Rev Neurol. 2001;33:1120-5.

7. Acharya JN, Satischandra P, Asha T, Shankar SK. Lafora's disease in South India: a clinical, electrophysiologic, and pathologic study. Epilepsia. 1993;34:476-87

8. Calleja J, Carpizo R, Berciano J, Quintial C, Polo J. Serial waking-sleep EEGs and evolution of somatosensory potentials in Creutzfeldt-Jakob disease. Electroencephalogr Clin Neurophysiol. 1985;60:5048

9. Drislane FW. Visual evoked potentials. In: Blum AS, Rutkove SB, editors. The Clinical Neurophysiology Primer. Totowa: Humana Press; 2007. p. 461-74.

10. Serrao M, Cardinali P, Rossi P, Perrotta A, Bartolo M, Parisi L, et al. Spinal myoclonus with giant somatosensory evoked potentials and enhanced long-loop reflex: a case report. Funct Neurol. 2004;19:203-6. 